\title{
Color y arquitectura vernácula: la serranía suroeste sevillana
}

Pilar Zafra Costán, Centro de Documentación del IAPH

Desde muy temprano

el color rebasó las

fronteras de lo

funcional para penetrar

en el universo de lo

simbólico como

transmisor de ideas
"Lo que sabemos o lo que creemos afecta al modo en que vemos las cosas" Modos de Ver. John Berger

Tonos suaves perfilando cornisas, saturados e intensos recercando puertas y ventanas, poyetes y guardapolvos, componiendo zócalos o invadiendo toda la fachada; ocres y azules, almagras y alberos,... blancos de cal.

Es un hecho conocido que el empleo del color en la arquitectura se remonta a los orígenes de la civilización. Clave en los procesos de cognición de nuestro entorno y en esa vieja interacción hombre-naturaleza, el color representa uno de los aspectos que, de forma más categórica, condiciona la realidad que nos rodea, determinando el modo en que la percibimos, la identificamos, la interpretamos, la construimos, la modificamos y tornándose en el nexo de unión que ha permitido históricamente el establecimiento de relaciones dialécticas entre el yo, el nosotros y, nuestra referencia, el medio.

Utilizado para enfatizar el carácter del edificio, acentuar sus formas, su grado de compartimentación o la articulación de sus diferentes espacios, desde muy temprano rebasó las fronteras de lo funcional para penetrar en el universo de lo simbólico como transmisor de ideas, como artífice de un lenguaje visual codificado capaz de revelar desde la organización de una determinada estructura social, económica o de poder hasta enarbolar la vigencia de determinados credos o satisfacer necesidades estéticas. Por ende, su presencia como recurso cultural resulta fundamental en la comprensión de uno de los contextos patrimoniales que más y mejor nos definen: la arquitectura vernácula. Este término hace referencia al modo en que se generan modelos arquitectónicos como respuestas a las necesidades físicas y sociales de un colectivo, "empleando los recursos naturales disponibles, pero seleccionándolos y elaborándolos para crear un hábitat adaptado a las necesidades socioeconómicas -junto a otras funciones culturales de carácter más simbólico-, de quienes las han habitado" (AGUDO, 1999).

Expresión material del hombre en su capacidad de crear cultura, de imponer sus criterios incluso sobre el propio medio, estas edificaciones remiten no sólo a las dimensiones constructivas, estéticas o artísticas, sino 


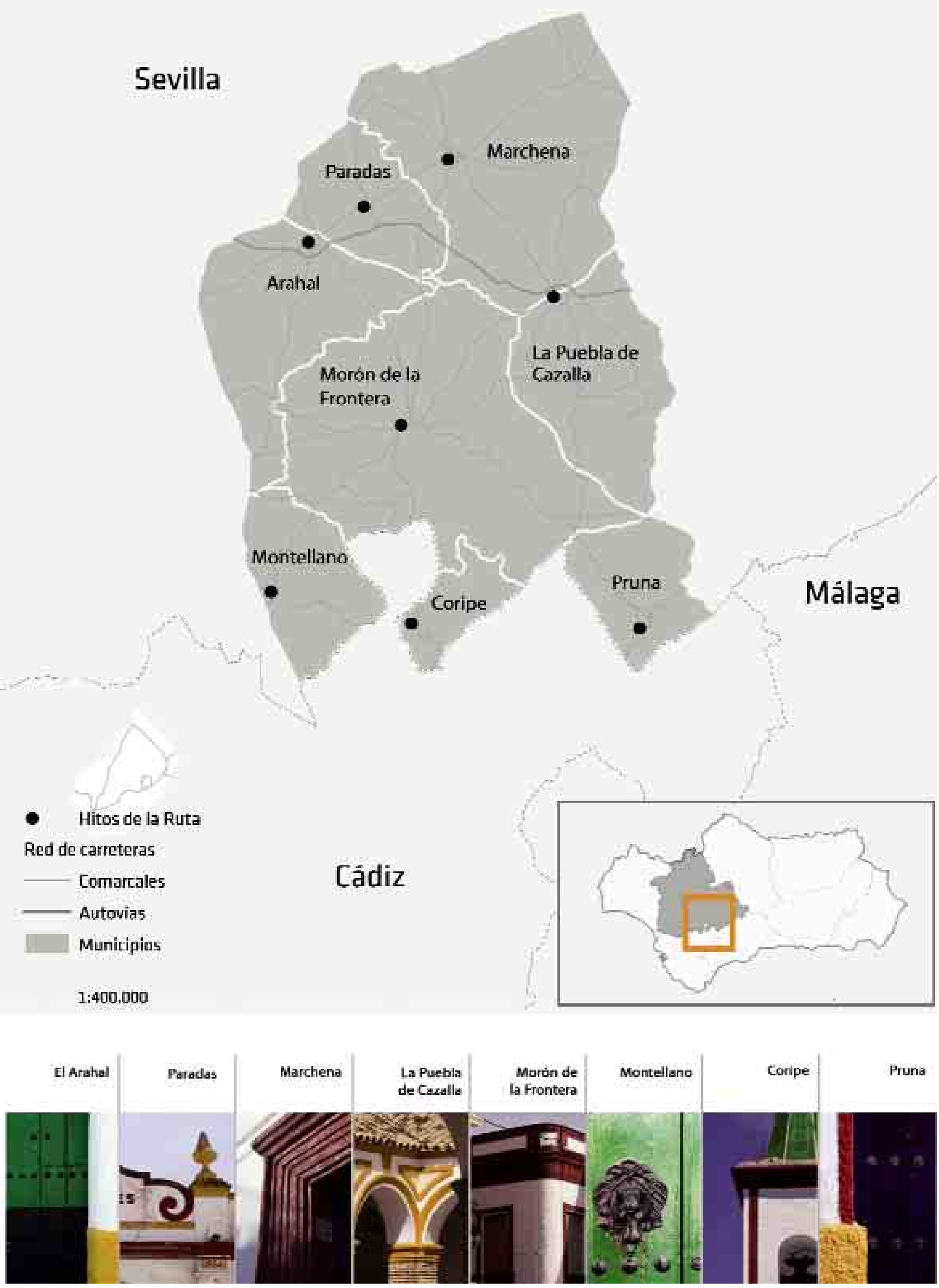


también a las identitarias como resultado de la conjunción de innumerables variables a tener en cuenta. La diversidad ecológica; las experiencias históricas, responsables de la aplicación de determinadas técnicas constructivas, de la planificación urbanística, organización y características de los espacios construidos, de sus usos sociales y significados simbólicos; la diversificación de actividades productivas; o las diferencias internas que han conformado la estructura social andaluza en los ámbitos rurales, derivadas del sistema agrario andaluz con sus polos extremos producto del latifundismo.

Denostada por su carácter funcional, por no contar con nombres y apellidos; condenada en muchos casos al olvido por no compartir los valores de singularidad y monumentalidad tradicionalmente considerados desde la tutela patrimonial; o reclamada por una sociedad actual necesitada de tradición, de referentes, que no ha dudado en recrear estereotipos mistificados de lo popular de un marcado carácter homogeneizador -acromatismo como rasgo distintivo de los caseríos andaluces-, esta arquitectura de lo disponible, sincera, que muestra sin pudor su sistema constructivo, constituye una de las señas de identidad más representativas de nuestro entorno y por sí misma, en su riqueza y diversidad, ha de ser valorada como un elemento cultural de enorme potencial.

Un horizonte de tierras calmas, en el que no existen límites aparentes para la visión, perfilado por los contornos suaves y la cadencia de las ondulaciones de la campiña sevillana, cede el paso a otros pagos, más abruptos y recortados marcando la vertical que imponen las estribaciones de la Subbética, siluetas encontradas que conforman el marco territorial en el que se inscribe la serranía suroeste sevillana.

La convivencia de dos zonas geográficamente diferenciadas, La Campiña -El Arahal, Paradas y Marchena-, y la Sierra Sur -La Puebla de Cazalla, Morón de la Frontera, Montellano, Coripe y Pruna- en un mismo territorio, su his- tórico carácter fronterizo, en la secular pugna entre moros y cristianos, y el protagonismo de un paisaje fuertemente antropizado, salpicado de pequeñas manchas de bosque mediterráneo, zonas adehesadas, vinculadas con la tradición ganadera serrana, olivares y extensos labradíos de corte latifundista, conceden a estas tierras una dilatada singularidad cultural.

El municipio de Arahal inaugura el recorrido. Emplazado sobre una colina amesetada que se mira en el paisaje campiñés, ejemplifica los rasgos distintivos de la arquitectura vernácula que a duras penas perdura en los caseríos de estas tierras. Herederos del medio natural y condicionados por unos materiales de construcción -piedra, barro y madera combinados en múltiples formas- derivados del empleo de los recursos ecológicos disponibles, estos ámbitos rurales actúan como referencias territoriales y forman parte de las escenas de un paisaje que proyecta hacia éstos sus cualidades estéticas.

El contraste resultante de la coexistencia de zonas verdes y olivar y la alternancia estacional de siembras cerealistas, barbechos blancos de otoño e invierno y semillados de primaveraverano, componen un ciclo de gran unidad que encuentra su parangón en el repertorio cromático y textural del tejido urbano. Su morfología y estructura, determinada por el predominio de viviendas de crujías paralelas a fachada de una planta y soberao, como consecuencia de su origen como núcleo de explotación agraria, utiliza el lenguaje cromático como generador de referencias. De manera generalizada esta tendencia se acusa en el esquema compositivo de sus fachadas, caracterizadas, grosso modo, por vanos de acceso en planta baja con arcos rebajados y cierros laterales protegidos por rejas de forja sobre pretiles adelantados y con uno o dos vanos en planta alta. Esta tipología de viviendas es exponente de una estructura social histórica en la que cada clase construye dentro de un código compartido, que es el que muestra las diferencias. En función de la diferenciación social de sus habitantes, se aprecia una transformación 

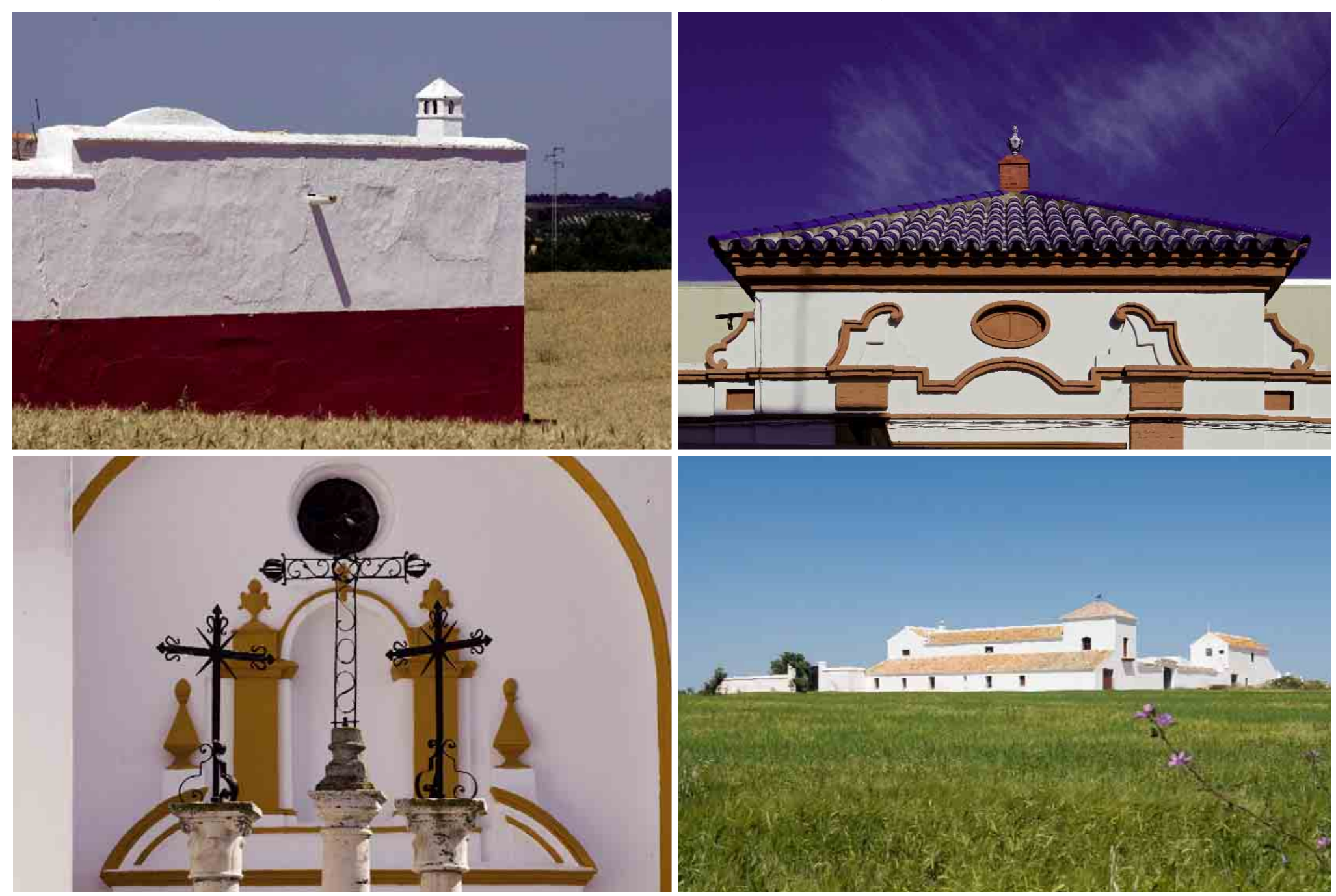

(1) Plaza del Convento (Puebla de Cazalla) / Foto: Juan CARLos CAZALLA, IAPH

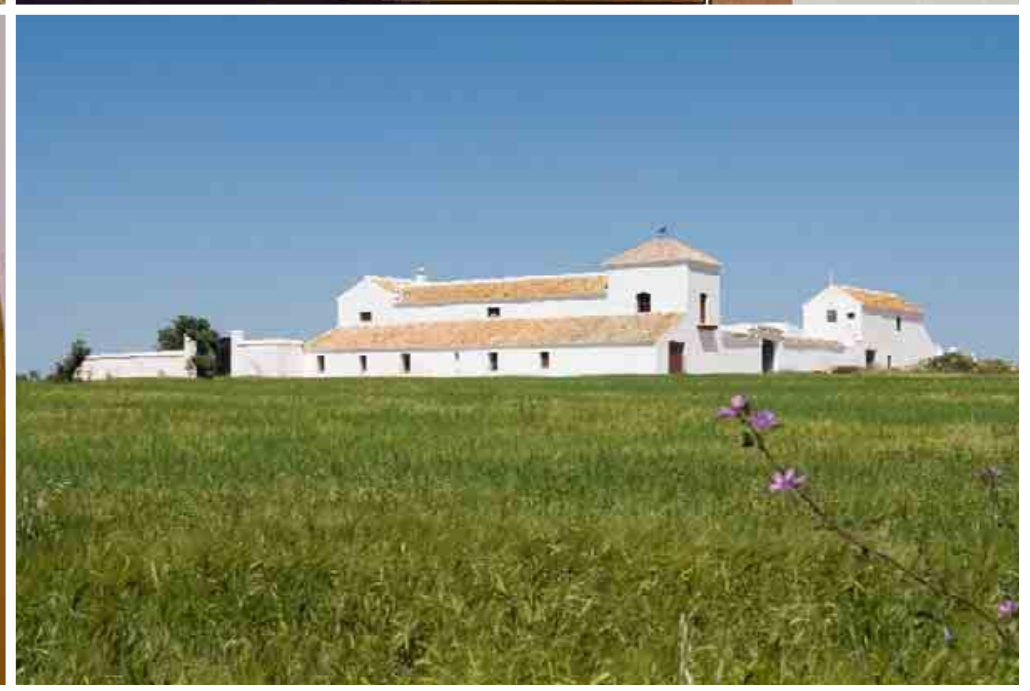

(1) Cortijo de labor en Marchena / Foto: JUAN CARLos CAZALLA, IAPH 


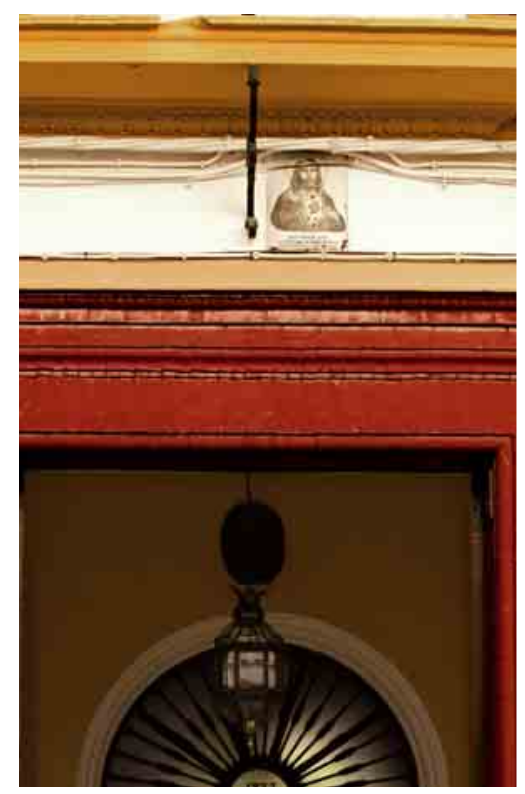

(1) Predominio del empleo del color en recercados de puertas y vanos (Marchena) / FOTO: JUAN CARLOS CAZALLA, IAPH

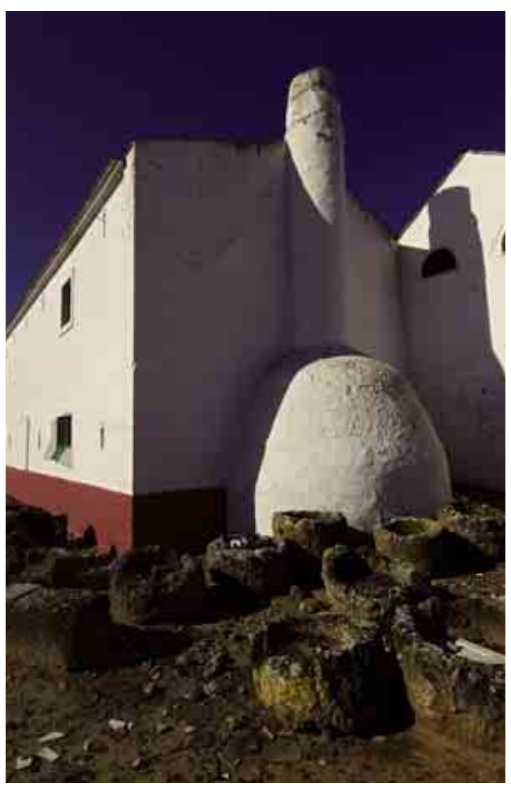

(1) Tiro de la chimenea. Hacienda la Banda (El Arahal) / Foto: JUAN CARLos CAZALLA, IAPH

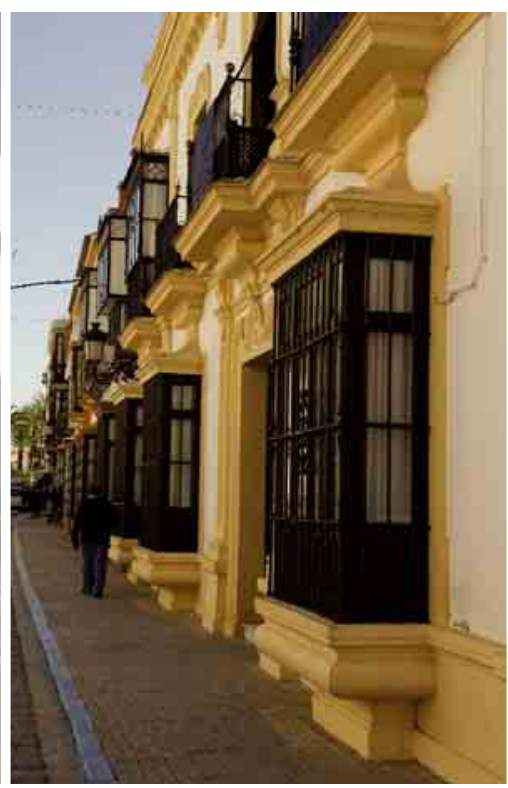

(1) Reiteración en el empleo del amarillo albero como elemento cromático. Calle de la Corredera en El Arahal / Foto: JuAN CARLos CAZALLA, IAPH

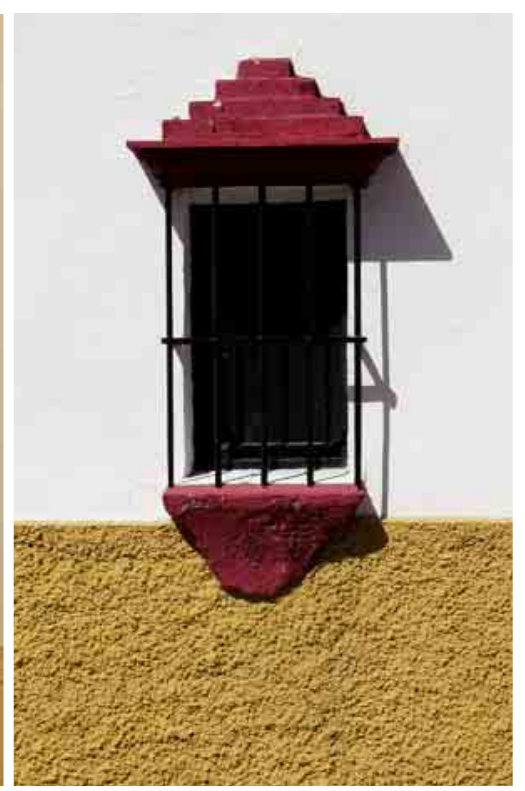

(1) Detalle de ventana de cierro

corrido con poyete y guardapolvo en rojo almagra que contrasta con el amarillo albero aplicado en zócalo (Pruna) / Foto: JUAN CARLOS CAZALLA, IAPH

Las portadas, vanos

y ornamentación expresan

material y simbólicamente la imagen representativa de la familia, su situación económica y el lugar que ocupan en la estratificación social de la comarca 


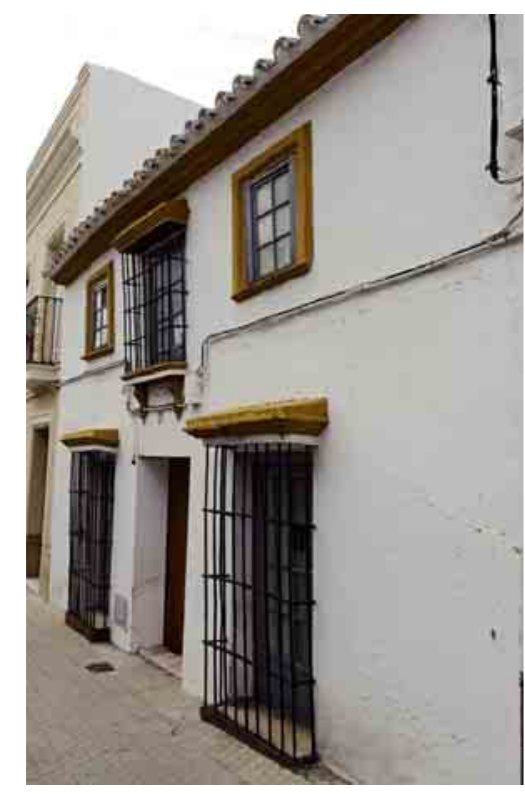

(1) El tiempo y las sucesivas manos de cal dotan a las paredes de una singular textura que se combina con detalles cromáticos. Calle Jerez Alto en Morón de la Frontera FOTO: JUAN CARLOS CAZALLA, IAPH

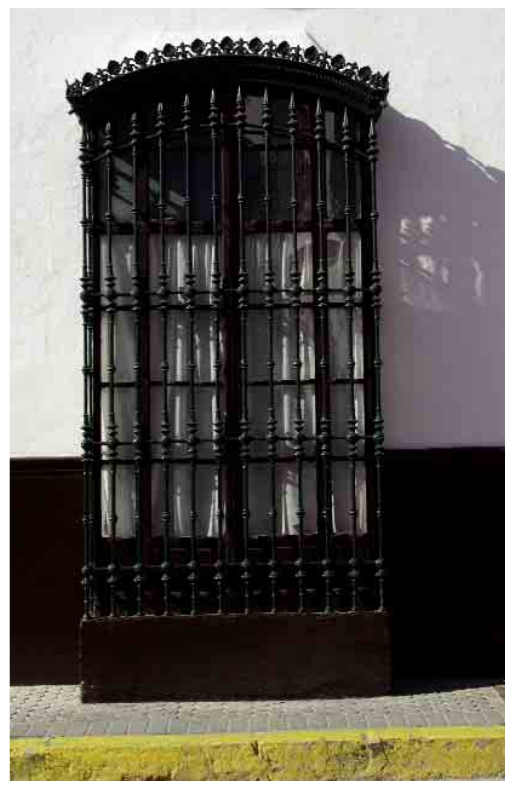

(1) Ventanal con reja voladiza sobre poyete corrido hasta el suelo. Acentuado por el empleo del color se perfila en un esmerado trabajo como quiebra momentánea del zócalo (Marchena) / FoTO: JUAN CARLOS CAZALLA, IAPH

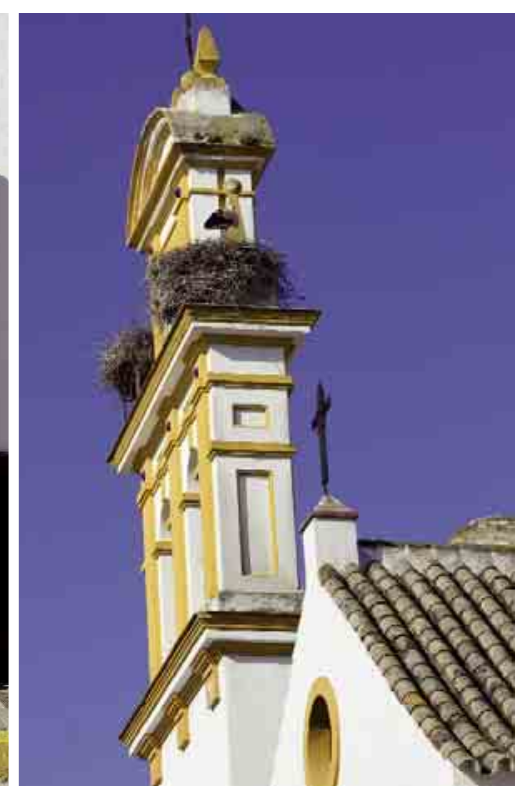

(1) Vista de la espadaña de la Capilla de la Vera Cruz en Marchena / Foto: JUAN CARLos CAZALla, IAPH

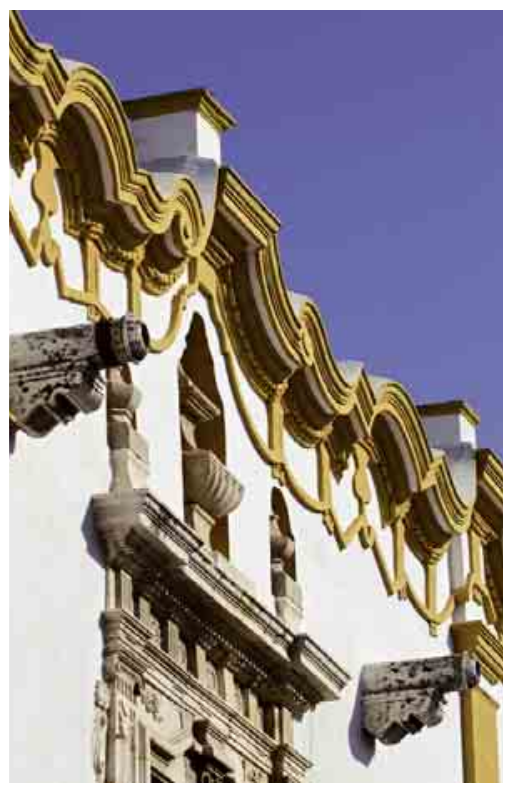

(1) Detalle de la portada de una de las viviendas de grandes propietarios que jalonan la calle San Pedro en Marchena / FOTO: JUAN CARLOS CAZALLA, IAPH sucesiva en el empleo del color desde la vivienda de pequeños propietarios, caracterizada por la pobreza de sus materiales o la ausencia de elementos ornamentales que suple, en muchos casos, con el resalte de sus elementos constructivos o la adición de pequeños detalles -incisiones en suelos, macetas en fachadas y policromías en zócalos y techumbres-, hasta las viviendas de grandes propietarios agrícolas, que exteriorizan su preeminencia social combinando el uso de materiales nobles como el mármol, la piedra o piezas cerámicas, los tipos de suelos formando dibujos y mosaicos, las cuidadas cornisas y aleros, o la utilización de recursos arquitectónicos procedentes de determinados estilos artísticos.

Reflejo de las situaciones de poder o dependencia, de dominio o subordinación y de respuesta a esta situación, la utilización del color, tanto en interiores como exteriores, se realizaba con pinturas o polvos colorados, amarillos, marrones, azules o verdes que, diluidos en turbios de aceite o aceite frito usado, se untaban en las solerías, los laterales de los empedrados, las cintas o los zócalos de los inmuebles, como lo atestigua el municipio de Paradas. Empleados indistintamente para marcar el carácter y definir la forma o simplemente para cubrir defectos, en el pasado los colores se elaboraban de forma manual, detectándose todavía en algunos inmuebles de la localidad la presencia de rojos -coloraos- en suelos, de verdes y amarillos en escaleras, cocinas o solerías, y de azules y marrones (claros u oscuros) en fachadas y vanos.

Asentada en el fértil valle del río Corbones, Marchena se encuadra dentro de los paisajes característicos de las campiñas del Guadalquivir y sus principales rasgos derivan de la actividad agrícola tradicional que ha ido intensificándose y ampliando su terrazgo, lo que ha propiciado la creación de infraestructuras para su transformación y almacenamiento. Insertos en estos paisajes, al igual que ocurre en el resto de los municipios de la comarca, entre los que ha de ser destacado el término de La Puebla de Cazalla, se disemi- nan un elevado número de cortijos, haciendas y lagares, en los que la proliferación del color se concentra en sus elementos ornamentales, herederos de los estilos artísticos imperantes durante su construcción, entre los que destaca el barroco, aunque también se pueden encontrar otros ejemplos de estilo industrial o historicista en sus variantes neogóticas, neomudéjares, regionalistas, etcétera. Sin embargo, por su pureza de líneas, el modelo más común es el caracterizado por el predominio de la cal en sus paramentos lisos y sus fachadas en resalte, de corte renacentista, donde se imponen los almagras y amarillos alberos. Sus portadas, vanos y ornamentación expresan material y simbólicamente la imagen representativa de la familia, su situación económica y el lugar que ocupan en la estratificación social de la comarca. "Demostración ésta, de que en la realidad social, expresada arquitectónicamente, las fronteras entre lo culto y lo popular no son claras, porque existe una gran permeabilidad de experiencias compartidas colectivamente" (CARRERA, 2004). 
Enclavada en una rica zona agrícola regada por los ríos Guadaira y Guadalete, entre la Sierra Sur y la Campiña, en pocos lugares podrá encontrarse una tradición tan antigua y fecunda en el trabajo de la cal como la que nació en el municipio de Morón de la Frontera, aún evidente en la Sierra de Montegil, en los hornos que salpican sus inmediaciones y en propia localidad, que junto con Montellano, de gran tradición calera aunque ya desaparecida, se constituyen como referentes paradigmáticos de la variedad de usos y significados de la cal.

El transcurso del tiempo y las sucesivas manos de cal dotan a las paredes de una singular textura que se combina con detalles cromáticos, aportados por el encuadre de puertas y ventanas o el resalte intencionado de los cantos de los paramentos, cuando no los propios suelos, escaleras, techumbres, cubiertas o cualquier otro elemento, expresando una finalidad funcional a la par que simbólica y estética. En su conjunto esta utilización de la cal, en armonía con el color, cómo se entremezclan, cómo se emplean o la importancia dada a uno u otro, testimonia igualmente los diferentes usos que de ella han hecho las distintas clases sociales. En gran medida su preponderancia en fachadas o interiores resulta proporcionalmente inversa a la jerarquía social. En las clases más pudientes, la cal se utiliza profusamente, representando a un tiempo limpieza y dignidad. En estos casos el color sirve precisamente para resaltar la imagen de blancura, mientras que en las grandes casas el predominio y variedad de colores actúa como llamada de atención hacia la propia complejidad arquitectónica.

Ventanas de rejas saledizas, con poyetes hasta el suelo, coronadas por guardapolvos resueltos en innumerables formas, emulando estilos más urbanos, puertas que realzan sus dinteles remarcando su perfiles, celosías y cierros que fuerzan el contraste, resueltos o reinterpretados con mayor o menor grado de complejidad y modestia, dada la enorme permeabilidad de estos esquemas compositivos a dife- rentes sectores sociales, y la alternancia de un expresivo juego de tonalidades, resumen la capacidad de formular, en esta parte de Andalucía, el modo, las maneras de habitar. En localidades como Coripe o Pruna, el grado de interrelación entre viviendas y calle resulta fundamental para llegar a comprender la importancia dada al color en la medida en que ésta no constituye sólo un lugar de paso, sino un importante espacio de sociabilidad.

Cada población, cada ciudad, cada comarca tiene una tonalidad propia. La diversidad de los materiales utilizados, el efecto de la luz, las texturas resultantes de la reiterada aplicación en el tiempo de sucesivas pátinas, son elementos que contribuyen a la formación territorial del color, a generar una determinada identidad cromática que referencia, haciendo visibles los modelos culturales del construir y del habitar. A la geografía física, a la geológica y climatológica, se une la geografía humana: costumbres y tradiciones locales que enriquecen la elección de tonalidades, armonizando según códigos sociales, culturales y religiosos.

La arquitectura vernácula y, por extensión, el uso que ésta hace del color, constituye, ciertamente, la piel de sus pobladores, contribuyendo a reafirmar la identidad de una región y los factores de diferenciación cultural que le dan razón de ser. Testimonios, en suma, de nuestras maneras de vivir en la continuidad del espacio y del tiempo. Quizás sólo por esto valga la pena aprender a mirar.

\author{
1. Detalle del campanario de la Iglesia de San Pedro en \\ Coripe, en el que la alternancia de almagras, verdes y blanco \\ de cal se emplea para enfatizar el carácter del edificio / \\ Foto: JUAN CARLOS CAZALLA, IAPH \\ 2. Calles de Pruna / \\ FOTO: JUAN CARLOS CAZALLA, IAPH \\ 3. Empleo de la cal como elemento decorativo, estético e \\ higiénico (Montellano) / \\ Foto: JUAN CARLOS CAZALLA, IAPH \\ 4. Calle San Pedro en Marchena / \\ FOTO: JUAN CARLOS CAZALLA, IAPH \\ 5. Detalle de la portada de la iglesia de San Antonio Abad \\ en Pruna / Foto: Juan CARLos CAZALLA, IAPH \\ 6. Remate de fachada en casa de calle La Carrera de Morón \\ de la Frontera / FOTO: JUAN CARLOS CAZALLA, IAPH \\ 7. Hacienda Las Huertas de las Monjas (Morón de la \\ Frontera) / Foto: JUAN CARLOS CAZALLA, IAPH
}




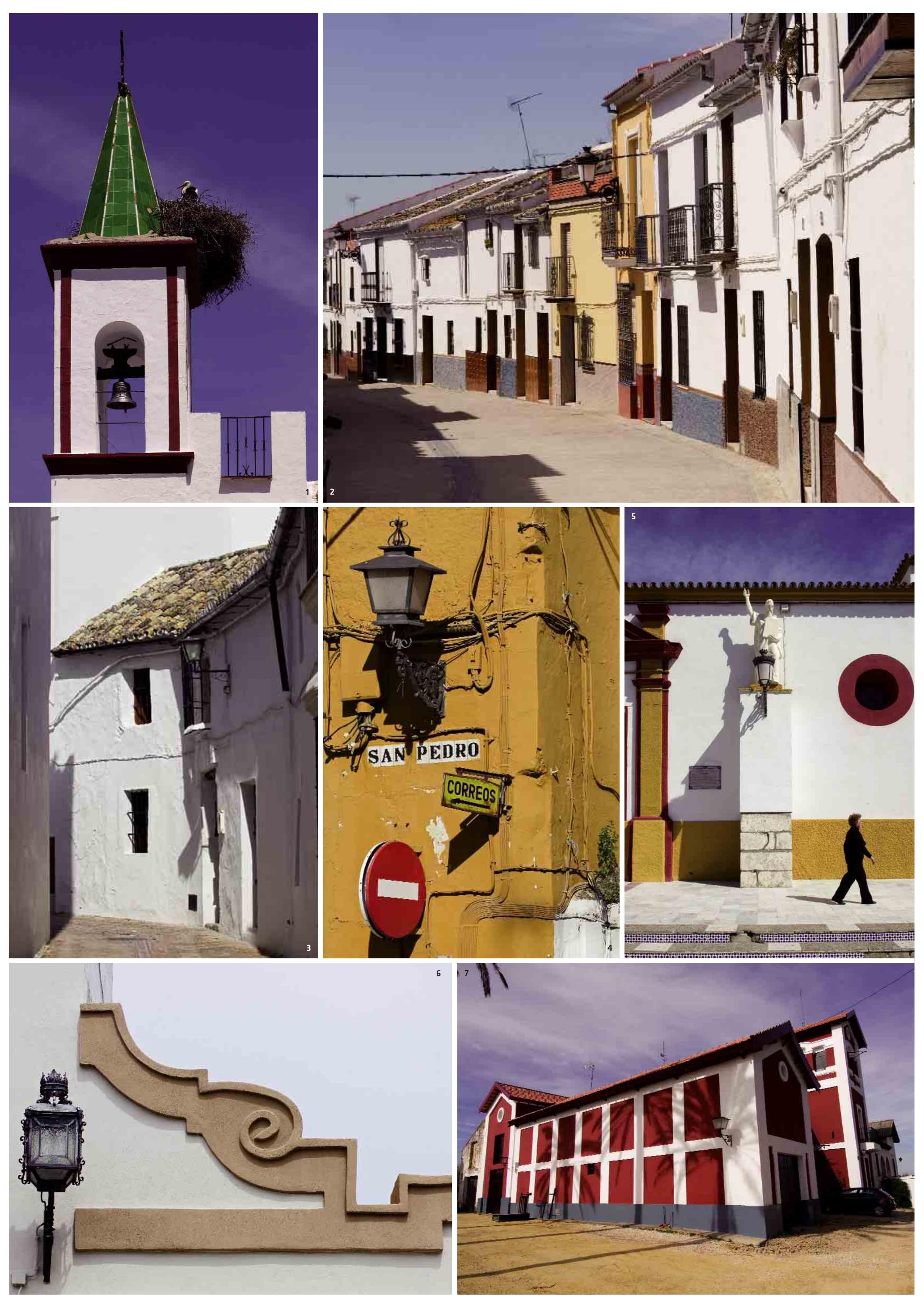

